Agro-Science Journal of Tropical Agriculture, Food, Environment and Extension Volume 13 Number 2 May 2014 pp. 1 - 6

ISSN III9-7455

\title{
PRICE GENERATING PROCESS AND VOLATILITY IN THE NIGERIAN AGRICULTURAL COMMODITIES MARKET
}

\author{
Ojogho $^{1}$ O. and R. A. Egware ${ }^{2}$ \\ ${ }^{1}$ Department of Agricultural Economics and Extension Services, Faculty of Agriculture, University of \\ Benin, Benin City E-mail: igomercy@yahoo.com \\ ${ }^{2}$ Department of Agricultural Economics and Extension Services, Faculty of Agriculture and \\ Agricultural Technology, Benson Idahosa University, Ugbor, Benin City
}

\begin{abstract}
The study examined the price generating process and volatility of Nigerian agricultural commodities market using secondary data for price series on meat, cereals, sugar, dairy and food for the period of January 1990 to February 2014. The data were analysed using both descriptive and inferential statistics. The descriptive statistics used the coefficient of variation while the inferential statistics used the linear Gaussian State-Space (SS) model. The results of the descriptive statistics showed that the coefficients of variation for cereals $(39.88 \%)$, food (32.65 $\%)$ and dairy price (43.08\%) were respectively higher during the overall time period (January 1990 to February 2014) than during the first (January 1990 to January 2002) and second (February 2002 to February 2014) subtime periods. The results of the inferential statistics showed that authoregressive moving average (ARMA) model is the most selected Nigeria agricultural commodity price generating model for the time periods, and that the final states of their unobserved component of cereals, meat, dairy and sugar prices were 6317.86, 2.06, 34.45 and 10.24 respectively. The prices of cereals, meat, dairy, sugar and food in general were generated and most fitted by the ARMA in Nigeria. Also the prices have been on the increase and have exhibited high volatility. The volatility, process and the determinants of the Nigerian food commodities prices can best be described by the simple (ARMA) model.
\end{abstract}

Keywords: price, volatility, state-space, stationarity, ARMA

\section{INTRODUCTION}

Price volatility is a normal feature of markets, especially in agricultural products market where prices tend to be more volatile due to seasonality, the derived nature of their demand, price-inelastic demand and supply functions, production uncertainty, and the fact that many agricultural products are perishable (Labys, 2003; Schnepf, 2005; Piot-Lepetit and M'Barek, 2011). In a market-oriented economy with perfect information, a key variable in the food system is the price of the commodity (White and Dawson, 2005; and Gortz and Weber, 1986 in Kuwornu et al., 2011). According to Gortz and Weber (1986) in Kuwornu et al., (2011), prices lead to revenues which provide incentives to participants through profits and losses. But not only are the data on prices uncertain and estimates from them rather imperfect measures, they differ substantially among themselves and from the commodities they explain with respect to the process generating them and some price indicators are unobservable while some contain coefficients are inherently time-varying making economic relationships potentially unstable. These dynamic properties cannot be observed directly from the data. A proper model for such dynamic process is the state space model which may be presented in their deterministic or stochastic form. The state space formulation can be used for a variety of models especially in regressions with timevarying coefficient and in the extraction of unobserved components from observed series (Harvey, 1984; 1989). (Wang, 2003; It shows great flexibility in that both simple and multiple classical regression models are easily fitted in the framework of state space modelling while providing a means to offset the time series models. Appropriate knowledge of the nature of commodity price variability, measure such variability of agricultural product prices, and evaluate the existence of a common price process among agricultural commodities and the effect of other unobservable impacting factors will not be out-of-place (Mittnik and Zadrozny, 2005; Ghysels and Valkanov, 
2006; Ghysels et al, 2006; Ghysels and Wright, 2008; Clements and Galvao, 2008; Marcellino and Schumacher, 2007; and Schumacher and Breitung, 2008). The study, therefore, examined the price generating process and volatility in the Nigerian agricultural commodities market. To achieve this, the study examined the time-varying variability model that best explain the price volatility in the Nigeria agricultural commodities market, measure such variability of agricultural product prices, and evaluate the existence of a common price process among agricultural commodities, and the effect of other unobservable impacting factors.

\section{MATERIALS AND METHOD}

The study used data published by the Food and Agriculture Organization (FAO) data set from both the Nigeria Statistical Bulletin, the World Trade Organisation (WTO) and the vintages of the World Bank database for price time series on meat, cereals, sugar, dairy and food in general for the period of January 1990 to February 2014 with less than 10\% missing data. The entire period was divided into two sub-periods. These are the first period (January 1990 to January 2002) and the second period (February 2002 to February 2014). The data were analysed using both descriptive and inferential statistics taking cue from Piot-Lepetit (2011). The descriptive statistics used the coefficient of variation while the inferential statistics fitted the the Autoregressive Conditional Heteroskedasticity (ARCH) model, the Generalised Autoregressive Conditional Heteroskedasticity (GARCH) model, the Exponential Generalised Autoregressive Conditional Heteroskedasticity (EGARCH) model and the Asymmetric Power Autoregressive Conditional Heteroskedasticity (APARCH) model using Eview 7.2 version to test for the best time-varying variability model that explains the price volatility in the Nigeria agricultural commodities market ranked according to three information criteria, the Schwarz Information Criterion (SIC), Akaike Information Criterion (AIC) and the Hannan-Quinn Information Criterion (HQIC). The data were first transformed to render them stationary by taking the first difference. The ARMA, ARCH, GARCH, EGARCH and APARCH used were ARCH (1), $\operatorname{GARCH}(1,1), \operatorname{EGARCH}(1,1)$ and $\operatorname{APARCH}(1$, $1)$, and given respectively as:

$$
\sigma_{t}^{2}=\alpha_{0}+\alpha_{1} \epsilon_{\mathrm{t}-1}^{2} \quad \text { ARCH (1) model }
$$

[1]

Where autoregression in its squared residuals has an order of 1 or has lag 1 $\sigma_{t}^{2}=\alpha_{0}+\alpha_{1} \epsilon_{\mathrm{t}-1}^{2}+\beta \sigma_{\mathrm{t}-1}^{2}$

GARCH

$(1,1)$ model

[2]

Where autoregression in its squared residuals has an order of 1 , and the moving average component has an order of 1 .

$\ln \left(\sigma_{t}^{2}\right)=\alpha_{0}+\beta \ln \left(\sigma_{\mathrm{t}-1}^{2}\right)+\alpha_{1}\left|\frac{\mid \epsilon_{\mathrm{t}-\mathrm{i}}}{\sigma_{\mathrm{t}-\mathrm{i}}}\right|-\sqrt{\frac{2}{\pi}} \mid-\gamma \frac{\epsilon_{\mathrm{t}-1}}{\sigma_{\mathrm{t}-1}}$

EGARCH $(1,1)$ model

[3]

$\left.\sigma_{t}^{2}=\alpha_{0}+\beta \sigma_{t-1}^{2}\right)+\alpha_{1}\left(\left|\epsilon_{t-1}\right|-\gamma \epsilon_{t-1}\right)^{2}$

PGARCH $(1,1)$ model

[4]

Where $\epsilon_{\mathrm{t}-1}^{2}$ is the ARCH term providing information about the volatility from previous period, $\sigma_{t-1}^{2}$ is the GARCH term measuring the last forecast variance while $\alpha, \beta$ and $\gamma$ are parameters to be estimated from the price series for the commodities. The model with the smallest value based on the criteria was then chosen as the best-fit model. The linear Gaussian multivariate state-space (SS) model for the discrete-time p-variate observable stochastic process was then used on the identified generating process. The state space, in matrix form, was given as:

$$
\begin{aligned}
& C_{\mathrm{t}}=\alpha_{\mathrm{t}}+\beta_{1} \mu_{\mathrm{t}}+\varepsilon_{\mathrm{t}}, \varepsilon_{\mathrm{t}} \sim N I D\left(0, \sigma_{\varepsilon}\right) \\
& \alpha_{\mathrm{t}}=\beta_{2} \alpha_{\mathrm{t}-1}+\exp \left(\beta_{\mathrm{a}}\right)+\epsilon_{\mathrm{t}}, \varepsilon_{\mathrm{t}} \sim N I D\left(0, \sigma_{\varepsilon}\right) \\
& \mu_{\mathrm{t}}=\alpha_{\mathrm{t}-1} \\
& F_{\mathrm{t}}=\gamma_{\mathrm{t}}+\delta_{1} \mu_{\mathrm{t}}+\varepsilon_{\mathrm{t}}, \varepsilon_{\mathrm{t}} \sim N I D\left(0, \sigma_{\varepsilon}\right) \\
& \gamma_{\mathrm{t}}=\delta_{2} \alpha_{\mathrm{t}-1}+\exp \left(\delta_{\mathrm{a}}\right)+\epsilon_{\mathrm{t}}, \varepsilon_{\mathrm{t}} \sim N I D\left(0, \sigma_{\varepsilon}\right) \\
& \mu_{\mathrm{t}}=\gamma_{\mathrm{t}-1} \\
& M_{\mathrm{t}}=\theta_{\mathrm{t}}+\vartheta_{1} \mu_{\mathrm{t}}+\varepsilon_{\mathrm{t}}, \varepsilon_{\mathrm{t}} \sim N I D\left(0, \sigma_{\varepsilon}\right) \\
& \theta_{\mathrm{t}}=\vartheta_{2} \theta_{\mathrm{t}-1}+\exp \left(\vartheta_{\mathrm{a}}\right)+\varepsilon_{\mathrm{t}}, \varepsilon_{\mathrm{t}} \sim N I D\left(0, \sigma_{\varepsilon}\right) \\
& \mu_{\mathrm{t}}=\theta_{\mathrm{t}-1}
\end{aligned}
$$$$
y_{t}=W_{t}^{*} \mu_{t}+\varepsilon_{t}, \quad \varepsilon_{t} \sim N I D\left(0, H_{t}\right) \quad \text { Observation }
$$

Equation

$\mu_{t+1}=F_{t}^{s} \mu_{t}+g \eta_{t}, \eta_{t} \sim N I D\left(0, Q_{t}\right)$ State Equation

Where the first equation is known as

The observation equation is for a $4 \times 1$ vector $y_{t}$ containing the values of the 4 observed time series at time point $t$. The $4 \times 1$ irregular vector $\varepsilon_{t}$ contains the 4 observation disturbances, one for each time series in $y_{t}$. The 4 observation disturbances are assumed to have zero means and an unknown variance-covariance $H_{t}$ of order $4 \times 4$. The $(5) \mathrm{m} \times 1$ state vector $\mu_{t}$ contains unobserved variables and unknown fixed effects. The matrix $W_{t}$ of order $4 \times m$ links the unobservable factors and regression effects of the state vector with the observation vector. The transition matrix $F_{t}$ is of order (10)m $\times m$. The $(16) r \times 1$ vector $\eta_{t}$ contains the state 
disturbances with zero means and unknown variances and covariances collected in the variance matrix $Q_{t}$ of order $\mathrm{r} \times \mathrm{r}$ structure represented by a variance matrix. and the second one is the state equation, $\boldsymbol{y}_{\boldsymbol{t}}$ is a vector of measured variables of dimension $4 \times 1, \boldsymbol{w}^{*}$ is vector of coefficients of dimension $\mathrm{p} \times \mathrm{p}, \boldsymbol{F}$ is vector of coefficients of the effect of past price state on the current price state, $\boldsymbol{g}$ is vector of coefficients of the effect of the error on current state, $\boldsymbol{x}_{\boldsymbol{t}}$ is the state vector of unobserved variables of dimension $\mathrm{p} \times 1$, which is a vector of unobserved components at time $t, p$ is the number of observation equations and $\varepsilon_{t} \sim N I D\left(0, \sigma_{\varepsilon}^{2}\right)$ and $\eta_{t} \sim N\left(0, \sigma_{\eta}^{2}\right)$ are the white noise. The transition matrix, $\boldsymbol{F}$, determines the dynamic properties of the state space model. The coefficient matrix $\boldsymbol{g}$ gives the variance structure of the state equation. $\sigma_{\varepsilon}^{2}$ and $\sigma_{\eta}^{2}$ are sometimes referred to as the hyper-parameters of the model, to distinguish them from the other parameters. The observation and state equations fitted into the ARMA $(1,1)$ models.

There are two main benefits to representing a dynamic system in state space form. First, the state space allows unobserved variables (known as the state variables) to be incorporated into, and estimated along with, the observable model. Second, state space models can be analyzed using a powerful recursive algorithm known as the Kalman (Bucy) filter. The Kalman filter algorithm has been used, among other things, to compute exact, finite sample forecasts for Gaussian ARMA models, multivariate (vector) ARMA models, MIMIC (multiple indicators and multiple causes), Markov switching models, and time varying (random) coefficient models.

\section{RESULTS AND DISCUSSION}

Table 1 shows the DF and ADF statistics for the variables. The Dickey-Fuller and ADF statistic values for the variables in their first difference form were lower than the critical values at $1 \%, 5 \%$ and $10 \%$, so that the null hypothesis that it has a unit root at first difference was rejected. However, the DF and ADF statistic values for the variables at level form were greater than the critical values at $1 \%, 5 \%$ and $10 \%$, so that the null hypothesis that it has a unit root at level form was not rejected. Augmented Dickey-Fuller (ADF) test for the variables indicate that all variables are non-stationary at levels but stationary at first difference. This implies that the results of the econometric analysis at the level of the series may not be suitable for policy making.

Table 2 shows the estimated coefficient of variation for prices of food items in Nigeria. The results show that for aggregate food price, the dispersion was $32.65 \%$ for the entire period and $11.47 \%$ and $30.26 \%$ respectively during the first (January 1990 to January 2002) and second (February 2002 to February 2014) sub-time periods. In the second sub-time period (February 2002 to February 2014), sugar price was the most dispersed $(45.23 \%)$, followed by the price of dairy products $(34.45 \%)$ while meat price had the least $(23.11 \%)$. The results also showed that the coefficients of variation for cereals price $(39.88 \%)$, aggregate food price $(32.65 \%)$ and dairy price $(43.08 \%)$ were respectively higher during the overall time period (January 1990 to February 2014) than during the first (January 1990 to January 2002) and second (February 2002 to February 2014) sub-time periods while the coefficients of variation for meat price $(21.40 \%)$ and sugar price $(43.89 \%)$ were respectively higher only during the overall time period (January 1990 to February 2014) than during the first (January 1990 to January 2002) sub-time period that corresponds to the possible price process existing before the recent price increase. When comparing coefficients of variation values between the sub-time periods 1990-2002 and 2002-2014, the values are higher for the second (February 2002 to February 2014) sub-time period for all food items than the first (January 1990 to January 2002) sub-time period. The highest increase is shown for sugar price from $23.48 \%$ to $45.23 \%$, followed by dairy price from $13.69 \%$ to $34.45 \%$. It may suggest that the Nigerian agricultural commodity prices have been on the increase. This is not unexpected as agricultural product markets experience not only price fluctuations from year to year but also volatile prices because of the relatively unstable conditions of supply and demand and the low elasticities of demand and supply (Schnepf, 2005; FAO, 2008; Trostle, 2008; Meyers and Meyer, 2009; Robles et al, 2009; 2010; 2009; Christiaensen, 2009; Gilbert, 2010) However, for an importing country like Nigeria, increasing prices would result in rising import bills with the attendant impact on the ability of poor consumers to purchase necessary food items. 
Price Generating Process and Volatility in the Nigerian Agricultural Commodities Market

Table 1: Dickey-Fuller and Augmented Dickey-Fuller Estimate for Stationarity

\begin{tabular}{lcccc}
\hline \multirow{2}{*}{ Variable } & \multicolumn{2}{c}{ Dickey-Fuller (DF) } & \multicolumn{2}{c}{ Augmented Dickey-Fuller (ADF) } \\
\cline { 2 - 5 } Cereals Price & Level & First Difference & \multicolumn{1}{c}{ Level } & First Difference \\
\cline { 2 - 5 } Food Price & -2.059 & $-6.590^{* * *}$ & -2.114 & $-6.545^{* * * *}$ \\
Meat Price & -0.838 & $-6.028^{* * *}$ & -0.900 & $-6.037^{* * * *}$ \\
Dairy Price & -1.734 & $-1.415^{* * *}$ & -1.704 & $-7.744^{* * *}$ \\
Sugar Price & 2.798 & $-8.634 * * *$ & 1.978 & $-8.531^{* * *}$ \\
\hline
\end{tabular}

Source: Authors' calculation, ${ }^{* * *}$ Significant at $1 \%$ level

Table 2: Estimated Coefficient of Variation for Agricultural Commodities Prices in Nigeria

\begin{tabular}{cccc}
\hline Variable & Entire Period & Coefficient of Variation & \\
\hline & $\mathbf{1 9 9 0 / 0 1 - 2 0 0 2 / 0 1}$ & $\mathbf{2 0 0 2 / 0 2 - 2 0 1 4 / 0 2}$ \\
CPI & $39.88 \%$ & $15.61 \%$ & $35.55 \%$ \\
FPI & $32.65 \%$ & $11.47 \%$ & $30.26 \%$ \\
MPI & $21.40 \%$ & $11.62 \%$ & $23.11 \%$ \\
DPI & $43.08 \%$ & $13.69 \%$ & $34.45 \%$ \\
SPI & $43.89 \%$ & $23.48 \%$ & $45.23 \%$ \\
\hline Source: Authors' calculation, CP is cereals price, FP is food price, MP is meat price, DP is dairy price and SP is sugar price
\end{tabular}

Table 3: Model for Food Items Prices and Their Selection Criteria

\begin{tabular}{|c|c|c|c|c|c|c|c|c|c|c|}
\hline \multirow[t]{2}{*}{ Variable } & \multicolumn{4}{|c|}{ Model for the Entire Period } & \multicolumn{3}{|c|}{ Model for 1990/01-2002/01 } & \multicolumn{3}{|c|}{ Model for 2002/02-2014/02 } \\
\hline & Model & AIC & SIC & HQIC & AIC & SIC & HQIC & AIC & SIC & HQIC \\
\hline Cereals & ARCH & 8.539 & 8.577 & 8.554 & 7.194 & 7.256 & 7.219 & 10.430 & 10.491 & 10.455 \\
\hline \multirow[t]{2}{*}{ Price } & GARCH & 8.542 & 8.593 & 8.562 & 7.194 & 7.276 & 7.227 & 10.458 & 10.540 & 10.491 \\
\hline & $\mathrm{ARCH}$ & 8.436 & 8.474 & 8.451 & 6.876 & 6.938 & 6.901 & 10.143 & 10.205 & 10.168 \\
\hline \multirow{3}{*}{ Food Price } & GARCH & 9.224 & 9.275 & 9.244 & 6.877 & 6.957 & 6.909 & 10.176 & 10.258 & 10.209 \\
\hline & EGARCH & 8.472 & 8.535 & 8.497 & 6.921 & 7.024 & 6.963 & 10.191 & 10.293 & 10.232 \\
\hline & ARCH & 8.197 & 8.235 & 8.212 & 7.507 & 7.569 & 7.532 & 8.963 & 9.025 & 8.988 \\
\hline \multirow{6}{*}{ Meat Price } & GARCH & 8.204 & 8.255 & 8.224 & 7.545 & 7.627 & 7.578 & 9.331 & 9.413 & 9.364 \\
\hline & EGARCH & 8.265 & 8.329 & 8.291 & 7.554 & 7.656 & 7.595 & 9.028 & 9.182 & 9.121 \\
\hline & $\mathrm{ARCH}$ & 9.012 & 9.050 & 9.027 & 7.404 & 7.466 & 7.429 & 9.923 & 9.984 & 9.948 \\
\hline & GARCH & 9.017 & 9.068 & 9.038 & 7.407 & 7.489 & 7.440 & 10.685 & 10.767 & 10.719 \\
\hline & $\mathrm{ARCH}$ & 10.091 & 10.139 & 10.106 & 9.178 & 9.240 & 9.204 & 11.042 & 11.104 & 11.067 \\
\hline & GARCH & 10.083 & 10.134 & 10.103 & 9.180 & 9.262 & 9.213 & 11.137 & 11.220 & 11.171 \\
\hline Sugar Price & EGARCH & 10.119 & 10.183 & 10.145 & 9.181 & 9.284 & 9.223 & 11.236 & 11.339 & 11.278 \\
\hline
\end{tabular}

Source: Authors' calculation, bold figures indicate criteria for selection

Table 3 presents the model for food items prices and the selection criteria. The results show that cereals price had 8.539 AIC criterion values as the smallest for the overall time series, 7.219 HQIC criterion value for the sub-period of 1990-2002 and 10.430 AIC value for the sub-time of 2002-2014. This implies that timevariant heteroscedastic cereals price variance model for Nigeria is the ARCH for the overall time series and the two sub-time period series. This implies that the today's time-variant heteroscedastic cereals price variance in Nigeria is a function of the one-time lag of its squared residuals. The future volatility of the cereals price in Nigeria is the sum of the current variance and the weighted one-period lag of the squared residuals.
Similarly, the model for aggregate food price is, most of the time, ARCH with the smallest AIC criteria values of 8.436 for the overall time series and 6.876 and 10.143 for the sub-time periods of 1990-2002 and 2002-2014 respectively. This implies that the future volatility of the aggregate food price in Nigeria is the sum of the current variance and the weighted oneperiod lag of its squared residuals. This is also true for meat price model with the smallest AIC criteria values of 8.197 for the overall time series and 7.507 and 8.963 respectively for the sub-time periods of 1990-2002 and 2002-2014 as it is also true for dairy and sugar prices. Thus, the ARCH model is most selected, thus the best, model to explain the volatility in the Nigeria agricultural commodities market. 
Table 4: Parameter Estimates of the State Space Model and their Associated Errors.

\begin{tabular}{|c|c|c|c|c|c|c|c|c|c|}
\hline \multicolumn{2}{|c|}{ Cereal } & \multicolumn{2}{|r|}{ Dairy } & \multicolumn{2}{|c|}{ Sugar } & \multicolumn{2}{|c|}{ Meat } & \multicolumn{2}{|c|}{ aggregate food } \\
\hline Parameters & Coefficients & $\begin{array}{l}\text { Parame } \\
\text { ters }\end{array}$ & Coefficients & $\begin{array}{l}\text { Parame } \\
\text { ters }\end{array}$ & Coefficients & Parameters & Coefficients & $\begin{array}{l}\text { Parameter } \\
\mathrm{s}\end{array}$ & Coefficients \\
\hline $\mathrm{C}(1)$ & $\begin{array}{l}- \\
0.999377 * * * * \\
(1.33 \mathrm{E}-09) \\
(-7.50 \mathrm{E}+08)\end{array}$ & $\mathrm{C}(10)$ & $\begin{array}{l}-0.205146 * * * \\
(1.59 \mathrm{E}-05) \\
(-12882.58)\end{array}$ & $\mathrm{C}(13)$ & $\begin{array}{l}0.143498^{* * * *} \\
(0.000206) \\
(698.2179)\end{array}$ & $\mathrm{C}(7)$ & $\begin{array}{l}0.281138^{* * * *} \\
(6.11 \mathrm{E}-07) \\
(460067.8)\end{array}$ & C(4) & $\begin{array}{l}0.151936^{* * * *} \\
(0.000288) \\
(527.4885)\end{array}$ \\
\hline $\mathrm{C}(2)$ & $\begin{array}{l}5.895796^{* * * *} \\
(0.050965) \\
(115.6836)\end{array}$ & $\mathrm{C}(11)$ & $\begin{array}{l}0.001209 * * * \\
(8.37 \mathrm{E}-06) \\
(144.4650)\end{array}$ & $\mathrm{C}(14)$ & $\begin{array}{l}- \\
0.032237 * * * \\
(3.59 \mathrm{E}-05) \\
(-897.3708)\end{array}$ & $\mathrm{C}(8)$ & $\begin{array}{l}1.21 \mathrm{E}-09 \\
(0.014495) \\
(8.32 \mathrm{E}-08)\end{array}$ & $C(5)$ & $\begin{array}{l}- \\
0.049987 * * * \\
(0.001540) \\
(-32.45918)\end{array}$ \\
\hline $\mathrm{C}(3)$ & $\begin{array}{l}- \\
0.892427 * * * \\
(8.90 \mathrm{E}-08) \\
(-10027943)\end{array}$ & $\mathrm{C}(12)$ & $\begin{array}{l}0.000817 \\
(0.000158) \\
(5.169147)\end{array}$ & $C(15)$ & $\begin{array}{l}0.041451^{* * * *} \\
(0.001559) \\
(26.58426)\end{array}$ & $\mathrm{C}(9)$ & $\begin{array}{l}1.67 \mathrm{E}-09 \\
(0.004196) \\
(3.99 \mathrm{E}-07)\end{array}$ & $C(6)$ & $\begin{array}{l}0.040756^{* * * *} \\
(1.67 \mathrm{E}-06) \\
(24367.19)\end{array}$ \\
\hline SV1 & $\begin{array}{l}6317.858 * * * * \\
(1.020809) \\
(6189.071)\end{array}$ & SV7 & $\begin{array}{l}34.44622 \\
(1.000409) \\
(34.43215)\end{array}$ & SV9 & $\begin{array}{l}10.24088^{* * * *} \\
(0.984011) \\
(10.40729)\end{array}$ & SV5 & $\begin{array}{l}2.061836 * * \\
(0.902512) \\
(2.284552)\end{array}$ & SV3 & $\begin{array}{l}8.61 \mathrm{E}-09 \\
(1.000000) \\
(8.61 \mathrm{E}-09)\end{array}$ \\
\hline SV2 & $\begin{array}{l}22472.48^{* * * *} \\
(0.075721) \\
(296780.8)\end{array}$ & SV8 & $\begin{array}{l}240.0462 * * * \\
(0.000000) \\
(\mathrm{NA})\end{array}$ & SV10 & $\begin{array}{l}247.0594 * * * \\
(0.000000) \\
(\mathrm{NA})\end{array}$ & SV6 & $\begin{array}{l}1704.978 \\
(2.98 \mathrm{E}-08) \\
(5.72 \mathrm{E}+10)\end{array}$ & SV4 & $\begin{array}{l}5.142912 \\
(0.985511) \\
(5.218524)\end{array}$ \\
\hline Log likelihood & $-8.16 \mathrm{E}+09$ & & & & & & & & \\
\hline Akaike info criterion & 56248263 & & & & & & & & \\
\hline Schwarz criterion & 56248263 & & & & & & & & \\
\hline $\begin{array}{l}\text { Hannan-Quinn } \\
\text { criterion }\end{array}$ & 56248263 & & & & & & & & \\
\hline
\end{tabular}

Source: Authors' calculation, ***Significant at $1 \%$ level, $* *$ Significant at $5 \%$ level

This implies that regarding the existence of a common price process in Nigeria, ARCH explains the price process for food in general, cereals, dairy, sugar and meat in particular. The volatility in agricultural commodities prices in Nigeria is the result of current variability and the weighted one-period lag of their squared residuals.

Table 4 shows the parameter estimates of the state space model and their associated errors. The results show that most of the coefficients were significant at the $1 \%$ level and, at convergence, that the maximum of the $\log$ likelihood was $-8.16 \times 10^{9}$. The coefficients $0.041,-0.205,0.001$ and -0.032 are the $\log$ variance of the error term for state equation of prices of cereals, meat, dairy and sugar. The respective variances of the errors are 1.042, 0.815, 1.001 and 0.969. The final states of seasonal and cyclical unobserved components for cereals, food aggregate, meat, dairy and sugar were respectively $22472.48, \quad 5.14, \quad 1704.98 \quad 240.05$ and 247.06. The coefficients $0.281,0.001,0.143$ and 0.041 are the respective effect of past price state of cereals, meat, dairy and sugar on their respective current price state. The values shown in the Table, 6317.86, 2.06, 34.45 and 10.24 are the one-step ahead predicted value for the first out-of-sample period for cereals, meat, dairy and sugar. 


\section{CONCLUSION}

The prices of cereals, meat, dairy, sugar and food in general were generated and most fitted by the ARMA in Nigeria. Also the prices have been on the increase and have exhibited high volatility. The volatility, process and the determinants of the Nigerian food commodities prices can best be described by the simple authoregressive moving average (ARMA) model.

\section{REFERENCES}

Clements, P. M and Galvao, A. B. (2008) Macroeconomic forecasting with mixedfrequency data: Forecasting US output growth," Journal of Business and Economic Statistics, forthcoming.

Christiaensen, L. (2009) Revisiting the Global Food Architecture. Lessons from the 2008 Crisis. Review of Business and Economics, 54, 345361.

Food and Agriculture Organization of the United Nations, FAO (2008) The state of food and agriculture-bio-fuels: prospects, risks, and opportunities. Rome: FAO.

Gilbert, C. L. (2010) How to understand high food prices. Journal of Agricultural Economics, 61, 398-425.

Ghysels, E.; Santa-Clara, P and Valkanov, R. (2006) Predicting Volatility: Getting the most out of return data sampled at different frequencies," Journal of Econometrics, 131(1-2), 59-95.

Ghysels, E. and R. Valkanov, R. (2006) Linear Time Series Processes with Mixed Data Sampling and MIDAS regressions models," mimeo, Chapel Hill, N.C.

Ghysels, E., and Wright, J. (2008) Forecasting Professional Forecasters," Journal of Business and Economic Statistics, forthcoming.

Harvey, A. C (1984) A Unified View of Statistical Forecasting Procedures. Journal of Forecasting, 3:245-275.

Harvey, A. C (1989) Forecasting, Strustural Timeseries Models and the Kelman Filter. Cambridge University Press.

Kuwornu, J. K. M; Mensah-Bonsu, A and Ibrahim, H. (2011) Analysis of Foodstuff Price Volatility in Ghana: Implications for Food Security. European Journal of Business and Management, 3(4): 100-118

Labys, W. C. (2003) New Directions in the Modeling and Forecasting of Commodity Markets. Mondes en Développement, 31(122), 3-19.

Marcellino, M., and Schumacher, C. (2007) Factor nowcasting of German GDP with ragged-edge data. A model comparison using MIDAS projections," Bundes bank Discussion Paper, Series 1 No. 34.

Meyers, W. H. and Meyer S. (2009) Causes and Implications of the Food Price Surge. http://www.fapri.missouri.edu/outreach/public ations/2008/FAPRI MU Report 12 08.pd

Mittnik, S., and Zadrozny, P. A. (2005) Forecasting quarterly German GDP at monthly intervals using monthly Ifo business conditions data," in Ifo survey data in business cycle and monetary policy analysis, ed. by J.E. Sturm, and T. Wollmersh Äauser, pp. 19\{48. Heidelberg: Physica-Verlag.

Piot-Lepetit, I. and M'Barek, R. (2011) Methods to Analyse Agricultural Commodity Price Volatility. Springer, New York.

Robles, M.; Torero, M. and von Braun J. (2009) When speculation matters. IFPRI. http://www.ifpri.org/sites/default/files/publicat ions/ib57.pdf

Schnepf, R. (2005) Price determination in agricultural commodity markets: a primer. CRS Congressional Research Service - Report for Congress, RL33204.

Schumacher, C. and Breitung, J. (2008) Real-time forecasting of German GDP based on a large factor model with monthly and quarterly data, International Journal of Forecasting 24, 386-398.

Trostle, R. (2008) Global agricultural supply and demand: factors contributing to the recent increase in food commodity prices. http://www.ers.usda.gov/Publications/WRS08 $01 /$

Wang, P. (2003) Financial Econometrics. Routledge. 